When symptoms of malacia become manifest in a hypophosphataemic patient histological confirmation of the diagnosis should be obtained and early aggressive treatment of the condition undertaken to prevent the rapid development of disabling bone disease. Aluminium hydroxide should be temporarily withdrawn and vitamin $\mathrm{D}$ should be given. Withdrawal of aluminium hydroxide may, by itself, be sufficient ${ }^{23}$ but as these patients are likely to be suffering from abnormalities of vitamin $\mathrm{D}$ metabolism also ${ }^{24}$ some form of vitamin D seems indicated. In addition, Jones ${ }^{17}$ showed that hypophosphataemic rickets in rats could be prevented or cured by vitamin $\mathrm{D}$.

This work was supported by the National Health and Medical Research Council of Australia and by the Postgraduate Medical Foundation, University of Sydney. Many of the biochemical determinations were performed in the laboratory of Dr F C Neale. Miss Margaret Wilkinson and Miss Debbie Steele gave valuable technical and secretarial help.

Requests for reprints should be addressed to Dr J F Mahony, Renal Unit, Sydney Hospital, Sydney 2000, Australia.

\author{
References \\ ${ }^{1}$ Pendras, J P, and Erickson, R V, Annals of Internal Medicine, 1966, 64, 293. \\ 2 Mallick, N P, and Berlyne, G M, Lancet, 1968, 2, 1316.
}

${ }^{3}$ Lotz, M, Zisman, E, and Bartter, F C, New England fournal of Medicine, 1968, 278, 409.

4 Lichtman, M A, Miller, D R, and Freeman, R B, New England fournal of Medicine, 1969, 280, 240.

5 Bishop, M C, Ledingham, J G G, and Oliver, D O, Proceedings of the European Dialysis and Transplant Association, 1971, 8, 106.

6 Bloom, W I, and Flinchum, D, fournal of the American Medical Association, 1960, 174, 1327

' Senior, B, American fournal of Diseases of Children, 1973, 125, 442.

${ }^{8}$ Garrick, R, Ireland, A W, and Posen, S, Annals of Internal Medicine, $C$ $1971,75,211$.

${ }^{9}$ Zettner, A, and Seligson, D, Clinical Chemistry, 1964, 10, 869.

10 Technicon Instruments Corporation, Chauncey, New York, 1960.

11 Young, D S, fournal of Clinical Pathology, 1966, 19, 397.

12 Morgenstern, S, et al, Clinical Chemistry, 1965, 11, 876.

13 Kleerekoper, M, et al, Clinical Chemistry, 1974, 20, 369.

14 Greulich, W W, and Pyle, S I, Radiographic Atlas of Skeletal Development of the Hand and Wrist, 2nd edn. Stanford, Stanford University Press, 1959.

${ }^{15}$ Garrick, R, Doman, P, and Posen, S, Clinical Science, 1972, 43, 789.

${ }^{16}$ Fournier, A E, et al, fournal of Clinical Investigation, 1971, 50, 592.

17 Deobald, H J, and Elvehjem, C A, American fournal of Physiology, 1935, $111,118$.

28 Jones, J H, American fournal of Physiology, 1938, 124, 230.

${ }^{19}$ Freeman, S, and McLean, F C, Archives of Pathology, 1941, 32, 387. 745.

21 Bishop, M C, et al, British Medical fournal, 1972, 3, 664

22 Pierides, A M, et al, British Medical fournal, 1976, 1, 190.

${ }^{23}$ Baker, L R, et al, British Medical fournal, 1974, 3, 150.

${ }^{24}$ De Luca, H F, fournal of Laboratory and Clinical Medicine, 1976, 87, 1.

\title{
Immediate plasma renin response to propranolol: differentiation between essential and renal hypertension
}

\author{
FALKO SKRABAL，WANDA CZAYKOWSKA， PETER DITTRICH， HERBERT BRAUNSTEINER
}

British Medical fournal, 1976, 2, 144-147

\section{Summary}

The immediate short-term effect on plasma renin activity of intravenous injection of propranolol was studied in 31 normal subjects and 166 hypertensive patients. In patients with essential hypertension and normal subjects plasma renin activity fell considerably within 15 minutes; the fall was directly proportional to initial plasma renin levels. In contrast, in patients with renal hypertension the fall was much less pronounced or totally absent. These differences in response to propranolol provide, though presently only on a group basis, a biochemical means of differentiating between patients with renal hypertension and those with essential hypertension. The observations also indicate that, unlike normal subjects and patients with essential hypertension, in patients with renal hypertension sympathetic activity plays no part in the control of basal plasma renin levels.

Department of Medicine, University of Innsbruck, Innsbruck A-6020, Austria

FALKO SKRABAL, MD, senior registrar

WANDA CZAYKOWSKA, BSC, member of scientific staff (present address: Endocrine Unit, Hammersmith Hospital, London W12 0HS)

PETER DITTRICH, MD, professor, head of haemodialysis unit HERBERT BRAUNSTEINER, MD, professor, head of department

\begin{abstract}
Introduction
Precision in endocrine diagnosis depends on the ability to measure all components of the feedback loops controlling hormone secretion. ${ }^{1}$ Nevertheless, renin levels in hypertensive 3 patients are commonly still being interpreted without considera-i tion of renal perfusion pressure, sodium concentration at the $\frac{O}{3}$ macula densa, or sympathetic tone at the juxtaglomerular apparatus, these probably being the main factors controlling $\supset$ renal renin release. ${ }^{2}$ None of the components of the feedback $N$ loops by which renin secretion is controlled is easily measurable $>$ in clinical practice. In an attempt to quantify sympathetic tone? at the juxtaglomerular apparatus we have taken the immediateN effect of acute beta-receptor blockade on basal plasma renin activity (PRA) as an indication of the extent to which renino release under basal conditions is mediated by the sympathetic nervous system. A preliminary account of part of this work has been published. ${ }^{3}$
\end{abstract}

\section{Patients and methods}

We studied (a) 31 normal volunteers (19 female and 12 male@ hospital employees), (b) 102 patients (61 women) with stable benigno essential hypertension (WHO stage 1 and 2), (c) 58 patients (30 women) 0 with well-established renal hypertension of comparable duration ando severity caused by chronic parenchymatous renal disease, and $(d)$ six patients (two women) on chronic intermittent haemodialysis witho hypertension of terminal renal failure.

Clinical details of the subjects are given in table I. Essential hypertension was diagnosed only after secondary forms of hypertension had been excluded by the usual diagnostic tests, which included urine analysis, blood chemistry, intravenous rapid-sequence 
TABLE I-Age, known duration of hypertension, 24-hour urinary sodium excretion (mean and range), PRA values, pulse rate, and blood pressure (mean $\pm 1 S D$ ) in normal subjects and patients with hypertension. Significances of differences are also given

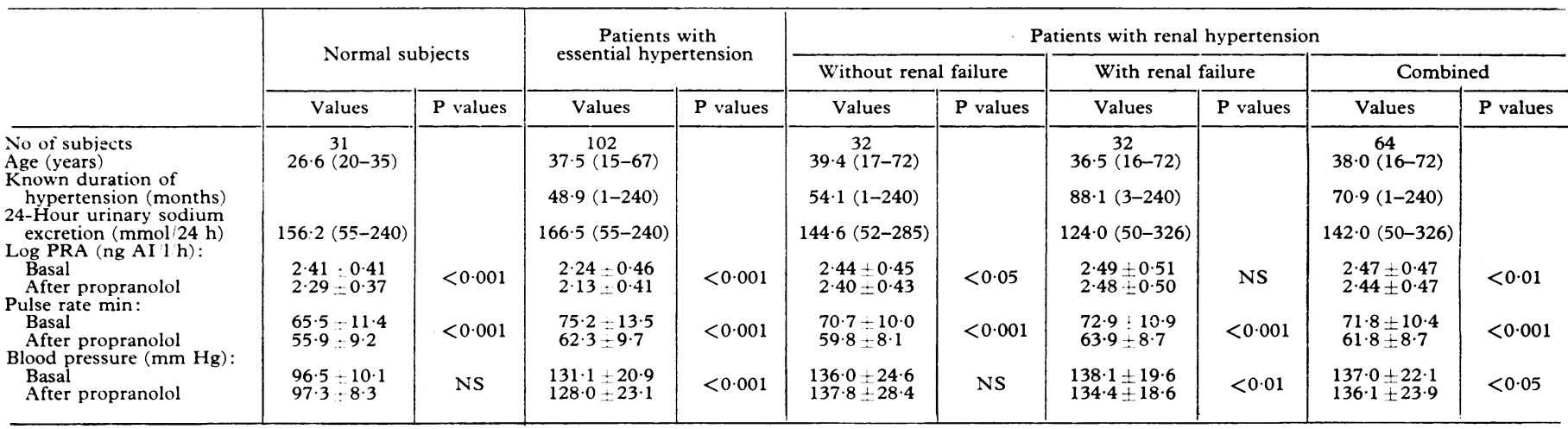

pyelography, determination of urinary catecholamines (in all patients), and renal arteriography (in patients under 35 years). The diagnoses of the patients with renal hypertension were: chronic bilateral pyelonephritis (16); chronic unilateral pyelonephritis (5); chronic glomerolonephritis, histologically confirmed (24); polycystic kidney disease (4); analgesic nephropathy (3); diabetic glomerulosclerosis (3); bilateral nephrocalcinosis and nephrolithiasis (1); and dysplastic kidneys (2). Thirty-two patients had normal serum creatinine levels; in 26 patients serum creatinine ranged from 159 to $707 \mathrm{umol} / \mathrm{l}$ 1.8 to $8 \mathrm{mg} / 100 \mathrm{ml}$ ). None of the patients had evidence of renal salt wasting or nephrotic syndrome.

All subjects were on an unrestricted (home) intake of sodium and potassium; hypertensive patients had stopped all medication at least two weeks before investigation. This seems to be a sufficiently long drug-free period. ${ }^{45}$ Forty-eight patients with essential hypertension and 38 with renal hypertension had never received any antihypertensive medication. Patients with evidence of congestive heart failure, atrioventricular block, or a history of bronchial asthma, and those receiving oral contraceptives or spironolactone were excluded from the study. The day before the study a 24 -hour urine collection was started for determining urinary sodium excretion. After an overnight fast and at least one hour's supine bed rest $5 \mathrm{ml}$ of blood for the determination of PRA was taken between $8 \mathrm{am}$ and $10 \mathrm{am}$. Propranolol $5 \mathrm{mg}$ was immediately administered intravenously over two minutes. Fifteen minutes after the beginning of the injection a second blood sample for determining PRA was taken. Blood pressures and pulse rates were recorded at the time the blood samples were withdrawn. In our experience and in that of others, ${ }^{6}$ one hour's bedrest is sufficient time to achieve basal PRA levels. The short interval of 15 minutes between the two samples was chosen to reduce any spontaneous variation of PRA. ${ }^{7}$ At the same time, this period should permit significant induced changes of PRA to occur, since it approximates to the normal half life of PRA. ${ }^{.-10}$ In six normal subjects the study was repeated two weeks later, but $5 \mathrm{ml}$ of $0.9^{\circ}$ o saline was injected instead of propranolol.

PRA was determined by radioimmunoassay by the method of Boyd et al."1 In our laboratory the intra-assay coefficient of variation for repeat determinations is $\pm 4^{\circ} \%$. This figure agrees closely with that reported by Boyd et al. ${ }^{11}$ With the given reproducibility, only changes in PRA greater than $10^{\circ}{ }_{0}$ were considered to be significant. Propranolol added to plasma samples before incubation did not affect PRA determination tested at concentrations of up to $20 \mathrm{mg} / \mathrm{l}$.

Standard methods were used for calculating means, standard deviations, and correlation coefficients; the difference in means between groups was assessed using Student's $t$ test.

\section{Results}

The means $( \pm S D)$ of basal and post-propranolol values of PRA, pulse rate, and blood pressure are shown in table I. Significant correlations between the different measurements are shown in table II. Within the given range of 24-hour urinary sodium excretion no significant correlation between sodium excretion and PRA was observed in either normal or hypertensive subjects. The frequency distribution of basal PRA in normal subjects and in patients with essential and renal hypertension is shown in fig 1 . This figure includes the values of 11 normal subjects in whom only basal PRA measurements were available.
TABLE II-Correlations between basal PRA and change in PRA after propranolol age, and known duration of hypertension.

\begin{tabular}{|c|c|c|c|c|c|c|}
\hline \multirow[t]{2}{*}{ Correlations } & \multicolumn{2}{|c|}{ Normal subjects } & \multicolumn{2}{|c|}{$\begin{array}{l}\text { Patients with } \\
\text { essential } \\
\text { hypertension }\end{array}$} & \multicolumn{2}{|c|}{$\begin{array}{l}\text { Patients with } \\
\text { renal } \\
\text { hypertension }\end{array}$} \\
\hline & r & $\mathbf{P}$ & $r$ & $\mathbf{P}$ & $r$ & $\mathbf{P}$ \\
\hline $\begin{array}{l}\text { Log basal PRA } v \\
\text { difference in PRA } \\
(\text { ("), after propranolol } \\
\text { Age } v \text { log PRA } \\
\text { Known duration of } \\
\text { hypertension } v \text { log } \\
\text { PRA }\end{array}$ & -0.65 & $<0.001$ & $\begin{array}{l}-0.62 \\
-0.46 \\
-0.20\end{array}$ & $\begin{array}{l}<0.001 \\
<0.001 \\
<0.05\end{array}$ & $\begin{array}{r}-0.23 \\
-0.32 \\
\\
0.02\end{array}$ & $\begin{array}{c}\text { NS } \\
<0 \cdot 01 \\
\text { NS }\end{array}$ \\
\hline
\end{tabular}

Renal hypertension $n=64$
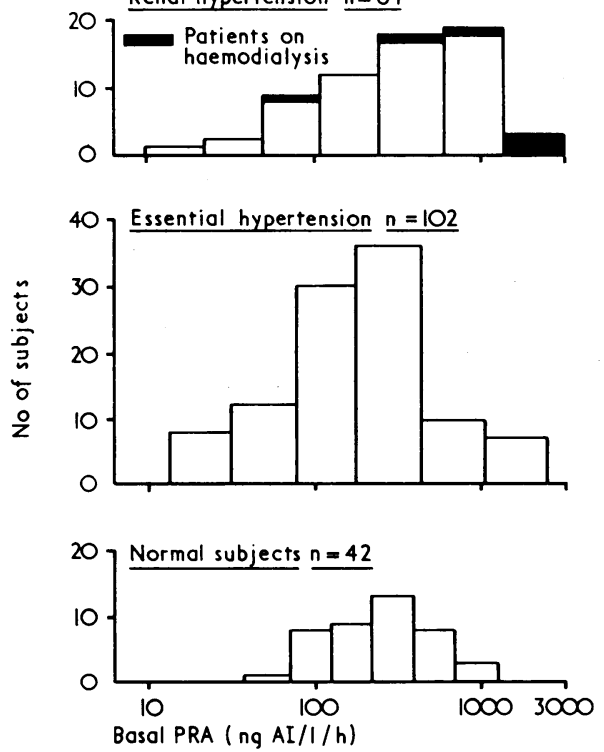

FIG 1-Distribution of basal plasma renin activity in hypertensive patients and normotensive controls. A log-normal distribution was confirmed by the Kolmogoroff-Smirnoff test only for normal subjects and patients with essential hypertension.

Response of PRA to propranolol in normal subjects-In normal subjects PRA decreased by up to $42 \%$ within 15 minutes (fig 2). The percentage decreases in PRA were significantly related to basal levels (see table II). PRA remained unchanged in six normal subjects after the administration of $0.9 \%$ saline.

Response of PRA to propranolol in hypertensive patients-Fig 3 shows the response of PRA to intravenous propranolol in patients with stable essential and renal hypertension, the subjects again being grouped according to their basal level of PRA. PRA fell significantly after propranolol in those patients with essential hypertension whose basal PRA was greater than $100 \mathrm{ng}$ angiotension $\mathrm{I} / \mathrm{1} /$ hour, the percentage decrease again being related to basal PRA (table II). In contrast, the fall in PRA after propranolol in patients with renal hypertension was 


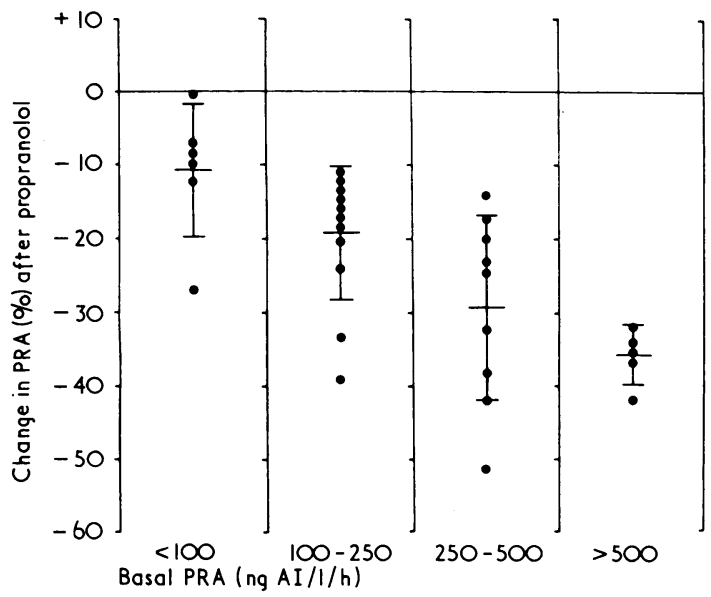

FIG 2-Mean fall ( \pm SD) in PRA 15 minutes after intravenous administration of $5 \mathrm{mg}$ propranolol in 31 normal subjects, grouped according to their basal levels of PRA.

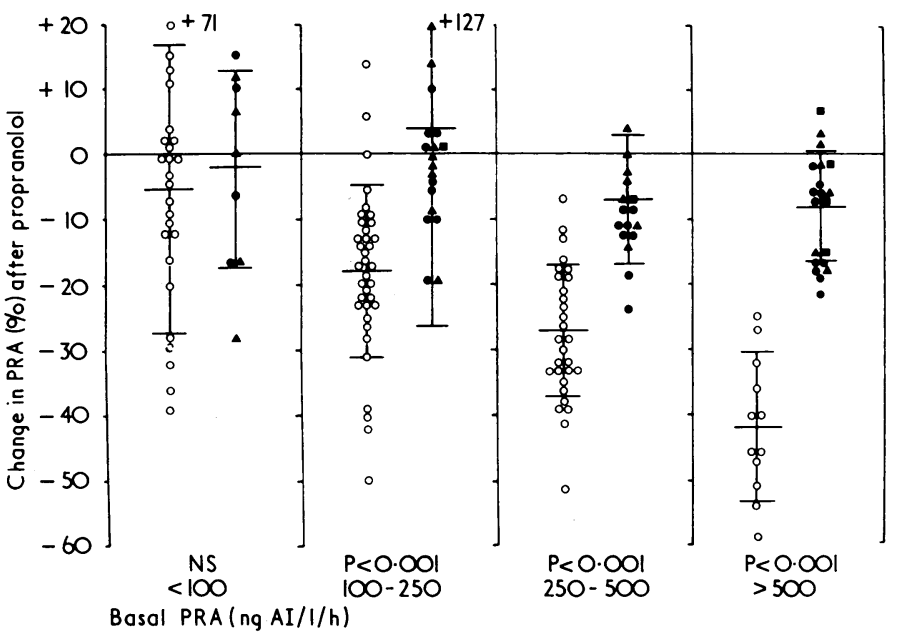

FIG 3-Changes in PRA 15 minutes after the intravenous administration of $5 \mathrm{mg}$ propranolol in 102 patients with essential hypertension $(O), 64$ patients with renal hypertension from chronic parenchymatous renal disease with normal $(\boldsymbol{O})$ and raised $(\boldsymbol{A})$ serum creatinine. $\mathbf{\square}=$ Patients on chronic intermittent haemodialysis.

uniformly less pronounced or absent. There was no correlation between basal PRA and the magnitude of decrease after propranolol (table II).

The pulse rate after propranolol decreased similarly in all subjects investigated; blood pressures did not change appreciably in any of the groups (table I).

\section{Discussion}

Propranolol inhibits the rise in PRA induced by orthostasis or by acute or chronic administration of diuretics in normal subjects and in patients with essential hypertension. ${ }^{12-14}$ The present study shows that propranolol also acutely lowers the previously unstimulated "basal" PRA after supine bed rest.

Since it is accepted that the fall in PRA after acute administration of propranolol is due to the inhibition of renin release, ${ }^{14} 15$ the magnitude of the decrease of PRA in our experiments seems to depend on two factors: the disappearance rate of renin activity from the circulation; and the extent to which basal release of renin is mediated by sympathetic tone. Given a half life of PRA of between 10 and 15 minutes, ${ }^{8-10}$ the fall in PRA should not exceed $50 \%$ after 15 minutes, even if PRA after supine rest were maintained solely by sympathetic activity. The maximum fall in PRA of between 50 and $60 \%$ observed in our study agrees with this. The highly significant correlation between basal PRA levels and the magnitude of decrease after propranolol suggests that sympathetic tone (sympathetic renal nerve activity or the level of circulating catecholamines, or both) is a major determinant of basal PRA in normal subjects as well as in patients with stable essential hypertension. No correlation has been $\underline{\underline{T}}$ observed between plasma noradrenaline levels and PRA ${ }^{16}$; since, 3 however, plasma noradrenaline has not been shown to reflect the $\stackrel{\mathbb{D}}{2}$ total sympathetic input to the kidney, our interpretation is still.. valid.

Since the rate of fall in PRA after propranolol in patients with $\stackrel{\overrightarrow{\mathcal{O}}}{\stackrel{\rho}{\mathscr{S}}}$ "high-renin" essential hypertension approximates to the maximal 음 possible decrease, taking into account the half life of PRA, high $\frac{\bar{\sigma}}{\bar{T}}$ basal PRA in benign essential hypertension may be maintained $\frac{0}{\vec{\sigma}}$ by increased sympathetic tone. This may explain the better $\mathbb{Q}$ hypotensive effect of propranolol in patients with high renin $\overbrace{}^{\circ}$ levels. ${ }^{1718}$

Since we could not show any substantial fall in PRA after propranolol in patients with renal hypertension even after $\overrightarrow{\vec{\omega}}$ prolonged intervals, ${ }^{19}$ it seems that an impaired removal of PRA from the circulation ${ }^{19: 0}$ is not the major explanation for the difference in response of PRA to propranolol between those with i essential and those with renal hypertension. Furthermore, there os is no evidence of a generally impaired responsiveness of the $\mathbb{\infty}_{\infty}$ sympathetic nervous system in patients with renal hypertension. The effect of propranolol on the cardiac beta-receptors seems to $\vec{f}$ have been comparable in normal subjects and in patients with $ᄋ$ essential and renal hypertension, as judged by the similar decreases in pulse rate in the three groups (table I). Hence $\overrightarrow{ }$ basal PRA in patients with renal hypertension seems to be maintained largely by factors other than sympathetic tone. The reduced renal perfusion, common to all patients with renal $\vec{\theta}$ hypertension, might indicate that the renal baroreceptors are responsible for mediating renin release.

One of the critical questions that arise from this study is whether the patients with benign essential hypertension had secondary hypertensive renal damage, which might have ٌ obscured any differences between essential and renal $\stackrel{\square}{\square}$ hypertension. Since the progressive renal abnormality produced $\stackrel{2}{\vec{T}}$ by long-standing hypertension apparently results in "low-renin" $\frac{0}{3}$ hypertension, ${ }^{21}{ }^{22}$ patients with long-standing essential hypertension should be found in the low-renin group, where no difference in the plasma renin response between essential and renal hypertension was observed. This is confirmed by the significant negative correlations between age, known duration of hypertension, and PRA observed in this series (table II). If $\frac{5}{3}$ patients with more advanced essential hypertension, in whom the onset of renal failure might be associated with a final rise in PRA again, ${ }^{23}$ had been included in our study we would not have expected to observe a difference between such patients and those with renal hypertension.

Plasma renin measurements in patients with essential and $D$ renal hypertension give values which range from low to very high levels (fig 1 ) and there is nothing to suggest that these two types of hypertension can be differentiated by measuring basal N PRA alone. Nevertheless, the present study shows that on a $\omega_{\sigma}$ group basis the immediate renin response to propranolol differentiates between patients with essential hypertension and $\stackrel{\circ}{=}$ those with renal hypertension. This differentiation may become $\stackrel{\mathbb{D}}{\mathcal{P}}$ diagnostically useful, for instance by optimising the time interval ${ }_{+}^{+}$ between sampling or by simultaneous consideration of the other components of the feedback loops controlling renin secretion.

We gratefully acknowledge the skilled technical help of Miss $\mathrm{A} \stackrel{\mathbb{Q}}{\varrho}$ Hiesmayr and Mr E Tögel. This work was supported by the Fonds zur Förderung der Wissenschaftlichen Forschung, Austria.

\section{References}

1 Parfitt, A M, Clinics in Endocrinology and Metabolism, 1974, 3, 454.

2 Davis, J O, American fournal of Medicine, 1973, 55, 333.

3 Skrabal, F, Klinische Wochenschrift, 1975, 53, 629.

${ }^{4}$ Lebel, M, et al, Lancet, 1974, 2, 308.

5 Morgan, T O, et al, Fournal of Clinical Pharmacology, 1975, 2, 159. 
${ }^{6}$ Pettinger, W A, and Mitchell, H C, New England fournal of Medicine, 1975, 292, 1214.

' Katz, F H, et al, fournal of Clinical Endocrinology and Metabolism, 1975, 40, 125.

- Michelakis, A M, and Mizukoski, H J, fournal of Clinical Endocrinology, $1971,33,27$

${ }^{9}$ Christlieb, A R, et al, Proceedings of the Society for Experimental Biology and Medicine, 1968, 128, 841.

10 Skrabal, F, and Czaykowska, W, Klinische Wochenschrift, 1974, 52, 1173.

${ }^{11}$ Boyd, G W, et al, Lancet, 1969, 1, 213.

12 Winer, N, et al, Clinical Endocrinology, 1969, 29, 1168.

${ }^{13}$ Michelakis, A M, and McAllister, R G, fournal of Clinical Endocrinology and Metabolism, 1972, 34, 386.
11 Bravo, E L, Tarazi, R C, and Dustan, H B, Fournal of Laboratory and Clinical Medicine, 1974, 83, 119

${ }^{15}$ Sullivan, J M, Adams, D F, and Hollenberg, N K, Clinical Research, $1973,21,453$.

${ }^{16}$ Louis, W J, et al, Circulation Research, 1974, 35, suppl No 1, p 57.

17 Bühler, F R, et al, New England fournal of Medicine, 1972, 287, 1209.

18 Karlberg, B E, et al, British Medical fournal, 1976, 1, 251.

${ }^{19}$ Skrabal, F, et al, Nieren und Hochdruckkrankheiten, 1976, 5, 1.

${ }^{20}$ Brown, J J, et al, Nephron, 1969, 6, 329.

21 Brown, J J, et al, Lancet, 1974, 2, 320.

22 Padfield, P L, et al, Lancet, 1975, 1, 548.

${ }^{23}$ Schalekamp, M A, et al, Ciba Symposium on Hypertension, Malta 1974, p 147. Horsham, Ciba Laboratories, 1975.

\title{
Enhanced drug metabolism in cigarette smokers
}

\author{
PRUE HART，G C FARRELL，W G E COOKSLEY， L W POWELL
}

effects of pentazocine, ${ }^{13}$ propoxyphene, ${ }^{14}$ and benzodiazepines. ${ }^{14}$ Although a recent study has provided more direct evidence that smoking stimulates drug metabolism by showing increased antipyrine clearance rates in smokers, ${ }^{6}$ these results varied considerably according to the age and other characteristics of the patients and could not be attributed solely to cigarette smoking. Smoking had no effect on diazepam plasma disappearance. ${ }^{15}$ Furthermore, although plasma levels of phenacetin are considerably lower in smokers than in non-smokers after comparable oral doses, there is no change in the plasma disappearance rate, and this probably reflects factors other than enhanced hepatic drug metabolism. ${ }^{16}$

We report here the results of a study designed to assess the effect of cigarette smoking on drug metabolism and to exclude both the influence of genetic variability and the effects of other environmental agents. This was done by studying a group of smokers before and after they had stopped smoking.

\section{Patients and methods}

The subjects studied were all healthy volunteers, some of whom were attending a hypnotherapy "stop-smoking" clinic. All gave informed consent. Subjects were excluded from the study if there was evidence of liver or renal disease or other disorders known to influence hepatic drug metabolism. ${ }^{17-20}$ Each volunteer was carefully questioned about his consumption of tobacco, alcohol, tea, and coffee and his use of pharmaceutical agents that may influence antipyrine half life. Those taking known hepatic microsomal enzyme-inducing drugs were excluded, as were those consuming alcohol in moderate amounts ( $<50 \mathrm{~g}$ ethanol per day). Most smokers smoked more than 20 cigarettes per day, but all consumed at least 11 cigarettes a day or $60-85$ g (2-3 oz) tobacco a week. The non-smokers had not smoked at all for the previous six weeks. The average age of the smokers was 39 years (range 16-63 years) and that of the non-smokers 35 years (range 20-63 years). The subjects in each group were comparable in sex and consumption of coffee, tea, and alcohol.

Plasma or saliva antipyrine half lives, or both, were studied in 42 subjects (17 non-smokers and 25 smokers). Several people were studied more than once to assess intraindividual variability and any difference in apparent antipyrine half life due to different routes of drug administration (oral as opposed to intravenous) or method of sampling (saliva as opposed to plasma). Repeat studies were carried out in a manner identical to the initial studies. Eight smokers were also restudied about two months after they had stopped smoking. These subjects were then asked about changes in their life style other than stopping smoking.

An aqueous solution of antipyrine in a dose of $10 \mathrm{mg} / \mathrm{kg}$ body weight was either injected intravenously over 10 minutes or taken by mouth dissolved in $100 \mathrm{ml}$ of orange juice. Five or more samples of venous blood $(10 \mathrm{ml})$ or fresh saliva $(5 \mathrm{ml})$ were collected at intervals during the next 30 hours. The antipyrine concentration of each sample was

G C FARRELL, MB, MRACP, NH and MRC medical postgraduate research scholar

W G E COOKSLEY, MB, FRACP, senior lecturer (clinical) in medical biochemistry

L W POWELL, MD, FRACP, professor cï medicine 